\title{
Identidade(s) e identidade(s) docente(s)
}

\author{
Identity(ies) and Teacher Identity(ies)
}

\section{Maurício Estevam Cardoso ${ }^{1}$}

\section{RESUMO}

Este artigo analisa a temática da(s) identidade(s) docente(s). A partir de um problema específico de pesquisa, que trata das representações identitárias formuladas por duas entidades dos/as professores/ as de Minas Gerais em fins dos anos 1970 e início dos anos 1980, é analisado aqui como diferentes estudos abordaram a noção de identidade e de identidade profissional de docentes. Para fins de exposição, foram estabelecidas três subtemáticas: concepções de identidades profissionais, concepções de identidade social e repercussões do movimento sindical sobre as identidades docentes. Este estudo destaca duas vertentes básicas de compreensão do processo de construção das identidades docentes, uma que privilegia a construção das identidades a partir dos processos de socialização e outra que destaca a construção identitária a partir das lutas da categoria. A análise efetuada conclui que há uma tensão permanente que perpassa as formulações identitárias dos docentes, sendo constituídas a partir de processos dinâmicos, que podem conhecer fases de rupturas, de continuidades ou de reelaborações, que comportam múltiplas dimensões, sejam relacionadas aos contextos sócio-históricos, sejam relacionadas às múltiplas experiências relacionais individuais e coletivas pelas quais passam os docentes, tanto no exercício profissional quanto no que diz respeito aos seus pertencimentos sociais.

PALAVRAS-CHAVE: Identidade docente; Identidade profissional; Trabalhadores em educação.

\begin{abstract}
This article analyzes the theme of the teacher's identity / teachers' identities. Motivated by a specific research problem related to the identity representations formulated by two unions of public school teachers in Minas Gerais State in the late 1970s and early 1980s, an analysis was conducted on how different studies took an approach to the identity notion and to the teachers' professional identities. For exemplification purposes, three sub-themes were established: conceptions of professional identities, conceptions of social identity and repercussions of the union actions on the teachers' identities. This study highlights two basic aspects in understanding the construction of the teachers' identities: one that privileges the identity construction from socialization processes, and another that highlights the identity construction from class struggles. The analysis concluded that there is a constant tension that pervades the teachers' identity formulations, developed from dynamic processes which can meet ruptures and phases of continuity or restructuring, comprising multiple dimensions, either related to sociohistorical contexts, or to the many individual and collective relational experiments which they go through as teachers, both in professional practice and in terms of social inclusion. KEYWORDS: Teacher's identity; Professional identity; Education workers.
\end{abstract}


"A fragilidade e a condição eternamente provisória da identidade não podem mais ser ocultadas. O segredo foi revelado. Mas esse é um fato novo, muito recente."

Zygmunt Bauman

"Precisamos fazer com que o magistério seja mais que um sacerdócio. A pessoa não precisa fazer voto de pobreza para ser professor"2. Em entrevista a uma revista de circulação nacional, o ministro da educação do Governo Lula, Fernando Haddad, revela a permanência de uma representação acerca da identidade docente, a imagem do/a professor/a abnegado/a, a serviço de uma nobre missão, desprendido/a de ambições materiais. É o que Sarmento (2000) classifica como a construção de uma ordem simbólica por meio da "metáfora missionária", pela qual a profissão docente não é considerada como uma atividade social, mas "um serviço, a que se adere por vocação, que se desempenha com fervor e cujos ganhos são de natureza espiritual" (p. 217). O ministro aponta em seu discurso a presença, seja no senso comum, seja para formuladores locais de políticas e programas para educação, da disputa entre formas de representações e tentativas de elaboração e afirmação de outra determinada identidade docente.

No Brasil, desde o final da década de 70 do século XX, algumas entidades de professores/ as buscaram contrapor a essa representação missionária a noção de "trabalhadores da educação". Essa noção identifica os docentes como sujeitos que, em muitos aspectos, se assemelham aos operários, vivenciando os mesmos problemas, como longas jornadas de trabalho, distanciamento do controle do produto de seu trabalho, baixos salários. Portanto, os docentes deveriam se organizar nos moldes dos sindicatos, adotando formas de mobilização semelhantes aos demais operários. Essa concepção buscaria romper com a lógica da abnegação, do sacerdócio, visto

\footnotetext{
2 Entrevista concedida à Revista Isto é, edição de 28 de novembro de 2008. Disponível em <http://www. terra.com.br/istoe/edicoes/2039/artigo117700-1. htm> Acesso em jan. 2009.
}

que as condições de trabalho e salariais são questionadas, evidenciando uma nova postura em relação à imagem que o docente constrói para si e para a sociedade.

A partir do exposto acima, nos questionamos que tensões perpassam as formulações identitárias dos docentes - pois como afirma Bauman (2005), "a identidade é um conceito altamente contestado. Sempre que se ouvir essa palavra, pode-se estar certo de que está havendo uma batalha" (p. 83) -, como são construídas as representações acerca de sua imagem? Professor/a? Trabalhador? Profissional? Funcionário/a?

A complexidade da questão da(s) identidade(s) impõe ao pesquisador diferenciar os pressupostos a partir dos quais este conceito é formulado. De acordo com Dubar (2005, p. xx), não existe uma identidade em essência, imutável, que acompanhe o sujeito, ou um grupo social, ao longo de sua existência sem sofrer transformações. As identidades são construções sociais e de linguagens, são relativas a uma determinada época histórica, a um determinado contexto sócio-político, pois como afirma Martuccelli (2002), "nenhuma identidade pré-existe à sua construção" ( $p$. 407). Esses autores se contrapõem a uma visão "essencialista" da identidade, para a qual haveria uma identidade coerente e única que acompanharia o indivíduo por toda a vida. A essa visão propõem uma ideia "construtivista", que preconiza serem as identidades o resultado de construções sociais contingentes e históricas (Martuccelli, 2002, p. 407).

A partir da complexidade de apreensão desse conceito, partimos do pressuposto de que missão ou sacerdócio, trabalho ou profissão, expressam representações identitárias ligadas a contextos sócio-históricos específicos, representações essas que se entrecruzam, se contradizem, em um processo incessante de reelaboração. Porém, indagamos ao autor (Dubar, 2005) acerca das razões da pregnância de "antigas" concepções identitárias nos espíritos e nas ações desenvolvidas na atualidade, como menciona o atual ministro da educação do governo brasileiro. 


\section{$A(s)$ identidade(s) profissional(ais) docente(s): formações e atuações}

A partir da década de 90 do século XX diferentes países daAmérica Latina têm realizado, em graus variados de efetividade, reformas educacionais em seus sistemas de ensino. Para autores como Esteve (2006), seria uma autêntica revolução educacional, uma revolução silenciosa que implicaria uma "reconstrução dialética do existente". Nesse sentido, pondera que não há como compreender a amplitude das reformas nem mesmo implementá-las a contento - sem se levar em conta os papéis desempenhados pelos docentes em seu cotidiano, em suas interações sociais, pois "a transformação do trabalho cotidiano em sala de aula depende de pessoas com uma determinada sensibilidade, com uma determinada história pessoal, com uma concepção específica do ensino e que se formou como docente em um determinado contexto histórico" (ESTEVE, 2006, p. 21)3. Enfim, para o autor a efetividade das reformas depende de indivíduos que constroem suas identidades individuais, coletivas e profissionais, relacionadas a múltiplos fatores, incluindo o trabalho que exercem.

Mesmo sendo necessário relativizar o teor das mudanças na perspectiva apontada por Esteve (2006), questionando o grau dessa "revolução silenciosa"4, cabe destacar a relevância dada

\section{Texto original em espanhol. Tradução nossa.}

$4 \mathrm{Na}$ perspectiva da sociologia da regulação social, Barroso $(2005,2006)$ considera que as reformas iniciadas a partir dos anos 80 do século XX nos países europeus e nos anos 90 no contexto latino americano, se caracterizam pela adoção de medidas políticas e administrativas que têm como resultado a alteração dos modos de regulação dos poderes públicos no sistema escolar. 0 que evidenciaria, portanto, não uma "revolução", mas a adoção de um "novo estatuto à intervenção do Estado na condução das políticas públicas" (BARROSO, 2005, p. 727). Os novos modelos de regulação advindos com as reformas, de acordo com o autor, buscariam superar o modelo burocrático-profissional de regulação, buscando, na realidade, a transformação do sistema com vistas à sua manutenção. Essa perspectiva trazida por Barroso (2005, 2006), nos faz questionar a definição das reformas como uma revolução, como um processo movido por intencionalidades definidas a priori, quando "a diversidade de fontes e modos de regulação faz com que a coordenação, equilíbrio ou transformação do funcionamento do sistema educativo resultem mais da pelo autor à necessidade de se analisar as construções identitárias dos docentes e suas transformações para compreender seus impactos sobre as reformas educacionais a partir dos anos 1990. Essa postura vem reforçar a proposta em discussão nesse estudo, que busca compreender as concepções acerca da(s) identidade(s) docente(s) e suas (re)elaborações em diferentes contextos históricos.

Avalos(2006), porsuavez, analisaaemergência de um "nuevo profesionalismo" na atualidade, que se contraporia a um "profissionalismo tradicional", desenvolvido em um contexto no qual os docentes lutam pelo reconhecimento da docência enquanto profissão e pela melhoria das condições de trabalho, da formação inicial e das oportunidades de formação continuada. No contexto de desenvolvimento do "novo profissionalismo", seria acrescido a essa lista a exigência de qualidade do ensino ministrado aos/às alunos/as. Essa nova exigência pode se apresentar sob duas óticas, como uma forma de se desenvolver a autonomia dos docentes ou como uma forma de se exercer maior controle sobre seu trabalho (Avalos, 2006, p. 209). A autora considera, ainda, que os aspectos positivos ou negativos de se posicionar frente a esse novo modelo derivariam de maior ou menor grau de confiança social na capacidade dos docentes para exercerem controle sobre seu próprio trabalho e em responsabilizar-se pela qualidade do ensino mediante critérios definidos a partir de

interação dos vários dispositivos reguladores do que da aplicação linear de normas, regras e orientações oriundas do poder público. Por isso, mais do que falar de regulação seria melhor falar de 'multi-regulação', já que as ações que garantem o funcionamento do sistema educativo são determinadas por um feixe de dispositivos reguladores que muitas vezes se anulam entre si, ou pelo menos, relativizam a relação causal entre princípios, objetivos, processos e resultados" (BARROSO, 2005, p. 734). As transformações nos modos de regulação dependem, portanto, da ação de diferentes atores, através de processos de confrontação e negociação, daí a necessidade de se compreender os contextos sócio-históricos de construção de identidades pelos docentes, agentes que ganham uma centralidade nas reformas. Ver: BARROSO, João. O Estado, a educação e a regulação das políticas públicas. Educ. Soc., Campinas, vol. 26, n. 92, p. 725-751. Out. 2005. Disponível em http://www.cedes.unicamp. br; BARROSO, João (org.). A regulação das políticas públicas de educação: espaços, dinâmicas e atores. Lisboa: Educa, 2006. 
seu conhecimento experiencial e não através de um controle baseado em metas e resultados de avaliações externas aplicadas aos/às alunos/as para aferir o grau de aprendizagem.

Dessaforma, aautoraassociaaprofissionalidade docente ao domínio ou autocontrole pelo seu próprio trabalho, à semelhança das profissões liberais clássicas, onde a formação do profissional se inscreve na continuidade da prática da docência. Considera, também, que ocorre um processo de redefinição do conceito tradicional de profissão e aponta para a necessidade de se estabelecer uma reflexão acerca da identidade docente, pois essa redefinição do conceito de profissionalismo docente estaria marcada por tensões e contradições que afetariam essa identidade e o trabalho diário dos docentes.

Para Avalos (2006, p. 216), a identidade profissional docente não se forjaria exclusivamente nas instituições de formação, visto a presença da dualidadeentreas disciplinasespecíficas dasáreas do conhecimento e as disciplinas pedagógicas, geralmente com maior prestígio das primeiras, o que visaria a formação de especialistas - biólogos, matemáticos, historiadores, dentre outros - e não de professores/as. Ainda, de acordo com a autora, ao ingressar no magistério os docentes vão reinterpretando, ao longo do exercício profissional, sua auto-imagem, abandonando a representação que têm como especialistas e adquirindo uma auto-imagem ligada à docência, à imagem de educadores. Para a autora, verificase, portanto, uma experiência profissional onde são forjadas imagens - identidades - decorrentes das situações de trabalho.

Avalos (2006) propõe um esquema de tarefas e condições requeridas para a formação docente inicial e continuada com vistas a formar esse novo profissional. Trata-se de buscar ferramentas situacionais que possibilitem a reflexão sobre a identidade profissional docente, como um meio formativo capaz de desenvolver o que a autora chama de "manejo emocional" e "confiança profissional" dos docentes para se alcançar o que seria esse "novo profissionalismo" (AVALOS, 2006, p. 231-232).

Avalos (2006) aponta a necessidade de pesquisar as condições concretas de trabalho dos docentes para a compreensão de sua formação identitária, mas retém, entretanto, uma concepção unitária da identidade docente - uma concepção que preconiza a existência de uma identidade docente única, centrada em normas-regras-valores - que seria adquirida nos processos de formação profissional e com o exercício do ofício: "parece que uma vez que ingressam no exercício docente esta percepção de especialistas se modifica e gradualmente se assume a identidade docente" ${ }^{5}$ (AVALOS, 2006, p. 216. Grifo nosso).

Da analise apresentada pela autora, decorreria a co-presença em um contexto social de identidades possíveis que não se sobreporiam. Uma decorrente da formação profissional inicial, outra forjada pela experiência de trabalho e uma terceira, onde demandas relacionadas à qualidade da educação interviriam na formação de um novo profissional. No entanto, indaga-se a esta literatura acerca das sobreposições identitárias que se produzem ao longo de uma trajetória de vida e trabalho. Percebe-se ainda uma tensão que interferiria nesse novo profissionalismo, entre um controle externo sobre o trabalho docente, consubstanciando na busca da qualidade do ensino - podemos citar como exemplo, no Brasil, as chamadas avaliações sistêmicas, nas quais como resultado final se afere um índice (IDEB - Índice de Desenvolvimento da Educação Básica) aos municípios e mesmo às escolas, que a partir desse referencial se traçaria metas para melhoria da qualidade da educação - e um controle corporativo dessa qualidade.

As proposições de Esteve (2006) e Avalos (2006) indicam a relevância do tema "identidade" relacionando-o aos processos de transformações sociais em curso. O primeiro destaca os processos sócio-históricos definidores das identidades, a segunda aponta como a relação entre formação e ethos profissional é determinante para a construção da identidade docente. Portanto, esses autores acabam por evidenciar importantes dimensões constitutivas das identidades profissionais docentes: o contexto sócio-histórico configurador, a sua formação profissional inicial e a trajetória profissional individual ou de grupo.

5 Texto original em espanhol. Tradução nossa. 
As identidades construídas a partir das práticas profissionais têm sido objeto de análise da sociologia das profissões, especialmente a partir das abordagens mais recentes ${ }^{6}$. Há, nesta vertente, um interesse em desvendar os mecanismos de socialização profissional, uma preocupação em explicar a diversidade e a complexidade das situações que envolvem a análise das profissões relacionadas aos processos de construção de identidades sociais. Nas chamadas abordagens sistêmicas e comparativas há, segundo Rodrigues (2002), uma significativa mudança de perspectiva. As análises passam a focar os aspectos relacionados ao exercício profissional, e não às estruturas dos grupos profissionais, daí o interesse pelos aspectos relacionados aos processos de socialização como elementos centrais para a construção das identidades profissionais.

\section{Da sociologia das profissões às novas construções identitárias nos indivíduos e grupos}

Nome representativo no campo da sociologia das profissões é Claude Dubar (2005), cuja análise relaciona a formatação de identidades profissionais aos processos de socialização, em um movimento de "construção, desconstrução e reconstrução de identidades ligadas às diversas esferas de atividade (principalmente profissional) que cada um encontra durante sua vida e das quais deve aprender a tornar-se ator" (DUBAR, 2005, p. xvii).

6 Rodrigues (2002) identifica quatro períodos na história da sociologia das profissões: o primeiro seria o da definição do campo, dos trabalhos da década de 1930 até o final da década de 1960, tendo o paradigma funcionalista predominado neste período, mas já se apontando uma perspectiva alternativa com a tradição da chamada "Escola de Chicago" e do interacionismo simbólico; o segundo período é marcado pela crítica e reabilitação das profissões, florescendo na década de 1970; o terceiro período, que se desenvolve ao longo das décadas de 1970 e 1980, se caracteriza por uma pluralidade de orientações metodológicas, mas tendo como foco de abordagem a questão do poder das profissões; o quarto período, das abordagens mais recentes, marca a busca por modelos complexos, são as abordagens sistêmicas e comparativas.
Para Dubar (2005), a elaboração de formas identitárias $^{7}$ articula dois sentidos do termo socialização e do termo identidade: a socialização relacional dos atores em um contexto de ação, (re)elaborando "identidades para o outro"; e a socialização biográfica dos atores em uma trajetória social, (re)elaborando as "identidades para si". As identidades sociais e profissionais são, portanto, marcadas por essa dualidade entre o processo relacional (atos de atribuição) e o processo biográfico (atos de pertencimento) e devem ser consideradas em processos históricos específicos e em contextos simbólicos próprios, por isso afirma-se que "a identidade nunca é dada, ela sempre é construída e deverá ser (re)construída em uma incerteza maior ou menor e mais ou menos duradoura" (DUBAR, 2005, p. 135).

Dessa forma, a chave do processo de construção das identidades sociais/profissionais estaria em reduzir distâncias entre as "identidades para si" e as "identidades para o outro". A questão de pesquisa central na abordagem de Dubar (2005), portanto, envolve a maneira pela qual atores sociais se identificam uns com os outros e constroem simultaneamente uma imagem de si. Ou seja, a configuração de determinadas identidades sociais e/ou profissionais é forjada na tensão de processos relacionais e biográficos.

Esse aspecto destacado por Dubar (2005) é fundamental para a análise do objeto proposto. A emergência de uma determinada identidade, por exemplo, a de "trabalhadores em educação", seria marcada por processos contraditórios, tensões e incertezas entre as trajetórias biográficas decorrentes de experiências individuais e grupais e as situações relacionais vivenciadas em um determinado meio, seja o metier profissional ou social, por parte dos atores envolvidos. Sob essa ótica de análise, a construção de definições identitárias comportaria diversas dimensões, não se reduzindo à interiorização pelos atores sociais de categorias pré-estabelecidas, como

7 Após a primeira edição do livro "a socialização: construção das identidades sociais e profissionais" (1991) , o autor opta por usar o termo "forma identitária" no lugar de identidade. Para Dubar (2005), as "formas identitárias" seriam a busca pela "elucidação das formas de identificação socialmente pertinentes em uma esfera de ação determinada" (p. xx). 
as socioeconômicas (categoria socioprofissional ou origem social) ou socioculturais (nível escolar, origem étnica, gênero). O que deve ser levado em consideração no processo de construção de identidades, de acordo com Dubar (2005), seria o processo de socialização no qual estão envolvidos os atores sociais, como suas identidades sociais e profissionais são construídas nesse processo.

Para Dubar (2005), haveria, ainda, dois sistemas estruturantes de identidade, primeiro a partir de uma atividade instrumental, que une em torno dos processos de trabalho as finalidades econômicas e os meios técnicos e organizacionais para alcançá-los; segundo a partir de uma atividade comunicativa, que estrutura a interação entre os indivíduos - sua identidade - por meio das práticas linguísticas.

A partir de Dubar (2005) pode se considerar que os processos de constituição identitários envolvem as condições individuais e grupais de vida e trabalho, como também os meios técnicos disponíveis aos sujeitos, os docentes, por exemplo, nas escolas brasileiras, onde se estruturariam identificações com os trabalhadores assalariados. Mas, acrescenta o autor, as identidades são forjadas, também, por práticas linguísticas e finalidades de ações, que no caso dos docentes estruturariam identificações outras como: sacerdócio e/ou funcionários.

De acordo com o referencial de Dubar (2005) podemos considerar então a copresença de dois sistemas estruturantes em tensão, não inteiramente complementares, nas construções identitárias dos docentes. O primeiro decorrente da atividade instrumental e o segundo da atividade comunicativa. No entanto, em Dubar (2005) verifica-se, ainda, que as formas identitárias prevalecentes provêm da articulação de processos distintos de socialização, singularizando cada ator em uma profissão. Biografias, representações e atividade instrumental e comunicacional constituem para esse autor os elementos que configuram múltiplas identidades em cada um, sejam pessoas ou grupos, com aproximações e dissensos.

Cattonar (2001), por sua vez, retoma com Dubar (2005), a apreensão analítica do processo de construção identitária dos docentes, pois considera essa identidade profissional como uma das dimensões da identidade social desses atores. A autora, para desenvolver sua argumentação, tem por referente duas categorias propostas por Dubar $(2005)^{8}$ para caracterizar a socialização profissional dos docentes, especialmente a noção da identidade como um processo relacional, construído a partir da elaboração de atos de atribuição (identidade para o outro) e atos de pertencimento (identidade para si).

Com Dubar (2005) considera que a(s) identidade(s) profissional(ais) dos docentes, bem como de outras categorias profissionais, são uma das dimensões de sua identidade social, uma construção ao mesmo tempo individual e social, não se reduzindo a uma identidade que tem sua formação relacionada exclusivamente ao trabalho. Existe sim, de acordo com Cattonar (2001, p. 6), uma identidade comum a todos os docentes, uma "cultura profissional partilhada", caracterizada por modos de perceber, de agir particulares, a partir de normas-regras-valores próprios da profissão docente, uma cultura profissional que se realiza nas interações cotidianas. Para a autora essa cultura é mutável, não é algo dado, a-histórico. Essa identidadeprofissional pressupõeumasocialização específica, a profissional. Isso implica reconhecer no curso da atividade docente a capacidade de construir uma identidade específica, distinta, ao longo do processo de socialização ativo e interativo, porém, construção associada a outros processos sociais que, também, constituem o substrato para a construção identitária do profissional docente (Cattonar, 2001).

A autora reitera que essas identidades são, também, ligadas a múltiplas trajetórias dos indivíduos - familiares, escolares, profissionais e pertencimentos sociais - sexo, idade, religião, classe social etc. - e relacionada a um contexto temporal e espacial (Cattonar, 2001).

Nesse sentido, a autora argumenta que não se pode reduzir a identidade profissional docente somente a um sentimento subjetivo de pertencimento a uma coletividade, nem

8 A primeira edição do livro de Dubar, "la socialisation: construction des identités sociales et professionnelles" foi publicada na França em 1991. 
a um processo de mera assimilação de uma determinada cultura profissional.

Entretanto, a autora enfatiza a existência de uma cultura profissional homogênea, corroborando as teses funcionalistas da sociologia das profissões $^{9}$, mas amplia sua abordagem ao incorporar à sua análise os processos de socialização dos docentes. Para Cattonar (2001, p. 14) haveria duas dimensões da identidade profissional docente: uma constituída por um "núcleo central", que seria a dimensão que é partilhada pelo conjunto dos membros do grupo, marcado pela memória coletiva desse grupo e pelas normas-regras-valores aos quais se refere - aspecto tributário das análises funcionalistas da sociologia das profissões; outra constituída pelos conjuntos periféricos, que se constituem em princípios de diferenciação no interior do grupo profissional docente e por efeitos do contexto (efeito cultural da organização, do universo do trabalho) e variações individuais.

Para a autora, o "núcleo central" é relativamente estável, mas ele pode se transformar, notadamente quando as práticas novas ou de transformação do contexto colocam em xeque sua significação central e estabelecem uma "incoerência insuportável" quando as antigas identidades tornam-se problemáticas, quando novos modelos aparecem (Cattonar, 2001).

Este artigo indaga aos pesquisadores consultados (Dubar, 2005 e Cattonar, 2002) acerca da existência de possíveis tensões entre os sistemas estruturantes da formação identitária dos docentes. Ou seja, entre múltiplas experiências relacionais individuais e grupais capazes de forjar identidades e a diversidade das experiências de formação inicial e continuada dos docentes. Imagens e representações de si, para os outros

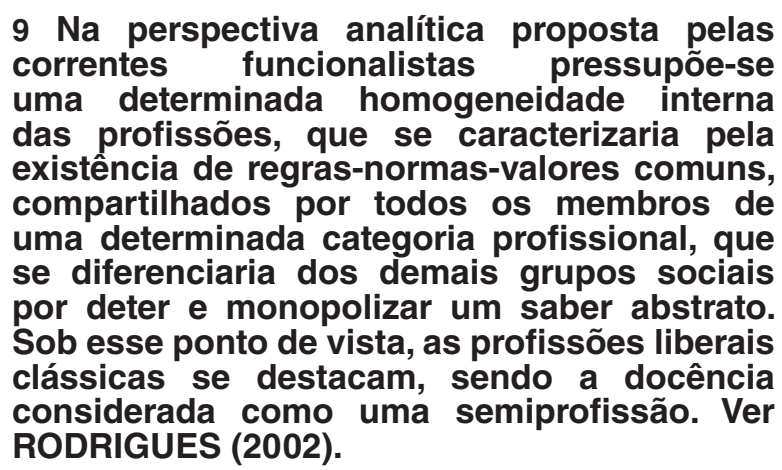

e dos outros, são configuradas e reconfiguradas, por pessoas e grupos que almejam e perdem em suas relações o(s) poder(es) de nomear. Por sua vez, certa padronização das ações relacionais e a redução de interações comunicativas decorrentes das condições de vida e trabalho tendem a conformar identidades comuns construídas em processos de socialização os mais diversos.

Tanto Cattonar (2001), quanto Dubar (2005) apontam para a necessidade de se compreender os processos estruturantes de construção das identidades, trabalham na perspectiva de conceber as identidades de forma plural, não se encerrando em apenas uma única dimensão. De acordo com esses autores, as identidades profissionais dos docentes são analisadas como um movimento, uma construção dinâmica, um processo contínuo, que pode conhecer fases de rupturas, de continuidades ou de reelaborações a partir de modelos anteriores de identificação. A nosso ver, esse aspecto é fundamental para podermos compreender possíveis tensões no processo de (re)formulação entre modelos identitários dos docentes, especialmente no contexto da emergência do termo "trabalhadores em educação". Para Dubar (2005) a(s) identidade(s) profissional(ais) de docentes estaria ligada a processos históricos de socialização em contextos específicos - identidades para outro - como também a trajetória singular de grupos ou indivíduos.

Em Cattonar (2001) um "núcleo central" identitário seria partilhado pelo conjunto dos profissionais, entretanto, se Dubar (2005) atenta para as práticas discursivas como elemento estruturante das identidades e a nosso ver em tensão com os elementos instrumentais que também a estruturam, o trabalho de Archer (2008) demonstra os efeitos desses dispositivos estruturantes sobre jovens acadêmicos ingleses.

Archer (2008) discute a questão da construção da identidade acadêmica frente às transformações engendradas pelas políticas neoliberais implementadas na Inglaterra a partir dos anos 1980, acarretando a mudança na natureza do trabalho acadêmico e nos papéis desempenhados pelos jovens acadêmicos, discutindo de que forma a introdução de sistemas 
de avaliação, lógicas de mercado, de inspeção e gerencialismo na educação superior têm afetado a reelaboração de uma identidade acadêmica.

Para Archer (2008), a partir das reformas neoliberais, uma nova identidade acadêmica foi se forjando em contraposição a uma identidade que seria construída a partir da interiorização de um conjunto de valores próprios da atividade profissional, em um processo de elaboração de identidades similares a de antigos colegas: valores do intelectual empenhado, crítico e profissional (materialização de princípios éticose responsabilidade com o trabalho, reafirmando o caráter virtuoso do discurso do profissionalismo). Essa concepção de identidade profissional apresentada por Archer (2008) aproxima-se da ideia de um "núcleo central" formulada por Cattonar (2001), pois haveria uma dimensão que seria partilhada pelo conjunto dos membros do grupo profissional docente, um conjunto de normas-regras-valores que se sustentariam em processos de memórias e reelaborações identitárias. O trabalho de Archer (2008) se orienta no sentido de se analisar o impacto das políticas e dos discursos neoliberais sobre esse "núcleo central".

Em suas conclusões Archer (2008) aponta como os jovens acadêmicos adotam a linguagem neoliberal em seu repertório (negócio, produtos, responsabilidade, qualidade, são termos recorrentes) e se é possível não se sujeitar à pressão neoliberal, criar uma subjetividade, uma identidade que não esteja ligada a essa lógica. A autora trata, portanto, dos contextos de ação dos jovens acadêmicos, do que Dubar (2005) estabelece como o sentido relacional dos processos de socialização, as "identidades para o outro", porém, ao dar ênfase a esse aspecto, acaba por desconsiderar os sentidos da socialização biográfica dos atores envolvidos no processo, ou seja, não leva em conta as "identidades para si" que são constantemente reelaborados nesse processo.

Entretanto, o trabalho de Archer (2008) fornece pistas de como o contexto de ação dos atores sociais pode ser um dos elementos determinantes para a construção de formas identitárias. Nessa pesquisa analisar a emergência do termo "trabalhadores em educação" no final dos anos 1970 objetiva apreender os impactos das novas configurações sócio-políticas sobre as representações identitárias que as entidades dos docentes constroem. De acordo com Sader (1988), essas configurações sócio-políticas que emergem nesse período são marcadas por uma crise de representação, manifestada em vários setores da sociedade: uma crise de representação da igreja, evidenciada nas formulações da "teologia da libertação"; uma crise no movimento sindical, que se expressaria na formulação de uma nova matriz discursiva do chamado "novo sindicalismo", e a crise das esquerdas, em decorrência do próprio histórico de derrotas sofridas a partir do golpe militar de 1964 e dos impasses internacionais.

\section{Identidade(s) profissional(ais) e identidade(s) social(ais)}

Ainda um aspecto relacionado às identidades profissionais dos docentes, ao qual é preciso estar atento, diz respeito aos princípios de identificação e diferenciação internas ao grupo profissional em questão, aos princípios de homogeneidade e heterogeneidade dessas identidades. Nessa linha, Hall (2006) ao analisar a existência de uma possível crise de identidade do "sujeito pós-moderno", aponta que esta seria marcada pela fragmentação da ideia de uma identidade unificada e estável. Esse sujeito seria, na realidade, portador de uma identidade "descentrada", não fixada, sem um caráter essencial ou permanente. A identidade seria, portanto, "uma 'celebração móvel': formada e transformada continuamente em relação às formas pelas quais somos representados ou interpelados nos sistemas culturais que nos rodeiam" (HALL, 2006, p. 13). Ao se pensar a emergência do termo "trabalhadores em educação", por exemplo, deve-se questionar até que ponto essa denominação comporta uma identidade única, inequívoca, estável ou se, ao contrário, não seria uma forte demonstração de uma identidade descentrada.

Hall (2006), ao analisar a tentativa de construção de uma identidade nacional argumenta que não importam as diferenças entre os membros de uma 
nação, seja em termos de classe, gênero ou raça, há sempre uma tentativa de unificá-los em uma mesma identidade cultural, a partir disso, propõe a seguinte questão: "mas seria a identidade nacional uma identidade unificadora desse tipo, uma identidade que anula e subordina a diferença cultural?" (HALL, 2006, p. 59). Essa questão poderia ser transposta para se pensar a construção de uma identidade centrada na ideia de "trabalhadores em educação", pois seria essa suficientemente forte e unificadora a ponto de subordinar formas identitárias diversas provenientes das interações comunicativas reiteradas quotidianamente? Ou ainda, de subordinar diferenças provenientes de trajetórias individuais e profissionais diversas, especialmente em um país onde o movimento operário era visto pelos setores hegemônicos como algo condenável?

Se hoje ainda constatamos a presença de imagem da profissão como sacerdócio ou de assistência social, como destacada na fala do ministro da educação, citada no início deste capítulo, significaria que as maneiras como foram construídos os discursos em torno da terminologia "trabalhadores em educação" seriam tentativas de anular outras formas tensionantes de construção identitária visando homogeneizar uma identidade social em detrimento das identidades profissionais?

Diferentes autores apresentam críticas a essa tentativa de se estabelecer uma identidade homogeneizadora. Para Sarmento (2000), quando analisa as lógicas de ação nas escolas, há por parte das instituições, como os sindicatos e associações profissionais, uma produção simbólica contínua, nas quais existem elementos que exercem "pressões uniformizadoras e tendências hegemônicas, mas a sua pluralidade [dos elementos simbólicos] permite também modos particularizados de interpretação e de conduta aos coletivos de professores e de alunos, com a afirmação de contratendências" (SARMENTO, 2000, p. 85). Para Martuccelli $(2002)^{10}$, essa tentativa de se estabelecer uma identidade homogeneizadora constitui-se em um dos extremos da tensão identitária, que buscaria

10 Texto original em francês. Tradução nossa. "afirmar uma espécie de essência comum a todos os membros de uma categoria, impondose assim uma base identitária supostamente mais profunda e substancial que a própria individualidade"(p. 419). ${ }^{11}$

A construção da crítica sobre as tentativas de homogeneização da identidade, como destaca Sarmento (2000), é um aspecto que deve ser levado em consideração ao se analisar a incorporação de um elemento simbólico comum que buscaria aglutinar todos/as os/as professores/ as, especialistas da educação, diretores/as de escola, cantineiras e faxineiros/as em torno da nomenclatura "trabalhadores da educação", desconsiderando-oubuscando intencionalmente anular - possíveis "contratendências" a uma forma identitária prevalente. Contratendências evidenciariam a presença de sistemas estruturantes de identidades profissionais em tensão e, também, evidenciariam contradições entre princípios de homogeneidade.

\section{Movimento sindical e identidade(s) docente(s)}

Em 1980 Arroyo publica artigo $^{12}$ com a seguinte questão-título, "operários e educadores se identificam: que rumos tomará a educação brasileira?". Pode se afirmar que nesse artigo Arroyo (1980) inaugura a discussão no Brasil sobre as transformações identitárias dos docentes em torno da ideia de "trabalhadores em educação". Sob o efeito das grandes greves operárias ocorridas no Brasil em 1978-79, o autor afirma o objetivo de compreender "o contexto educacional brasileiro" à luz da conjuntura sócio-política do período. Para o autor, esse contexto teria a marca de uma nova organização e participação

110 outro extremo dessa tensão identitária seria justamente o inverso, ou seja, assumir uma dispersão identitária virtual e ilimitada, como um "movimento 'fractal' de diferenças individuais" (MARTUCCELLI, 2002, p.419-420. (Tradução nossa)

12 ARROYO, Miguel. Operários e educadores se identificam: que rumos tomará a educação brasileira? Educação e Sociedade. São Paulo, v.2, n.5, jan.1980. p.5-23. Este artigo se originou a partir de uma comunicação apresentada no $2^{\circ}$ Encontro Nacional de Supervisores de Educação, realizado em Curitiba em outubro de 1979. 
das classes populares na vida do país, que por meio de "greves e pressões se situam dentro de um movimento profundo de transformação das relações sociais de produção, das relações de trabalho e das condições coletivas de vida dos trabalhadores", gerando uma "nova consciência e nova prática de classe" (ARROYO, 1980, p. 10).

Ao analisar as greves de professores de 19787913, Arroyo (1980) aponta a existência de uma solidariedade entre "trabalhadores da produção" e "trabalhadores do ensino" na luta contra a escola de caráter ideologicamente burguês. Esta solidariedade geraria uma identidade entre esses trabalhadores, pois os docentes foram se transformando em "força de trabalho" vendida ao "patrão Estado". Uma nova identidade docente para Arroyo (1980) se constituiria na luta por melhores condições de trabalho e salário, mas também na luta pela transformação da sociedade, a partir da solidariedade comum. A identificação com os demais trabalhadores adviria da tomada de uma "nova consciência" sobre a situação social brasileira e sobre a necessidade de se unir todo o movimento dos trabalhadores. O autor, portanto, projeta uma inevitabilidade da construção identitária ligada à ideia de "trabalhadores da educação", pois analisa que as contradições inerentes ao sistema capitalista forjariam uma tomada de consciência de classe por parte dos docentes, que se engajariam na luta pela transformação da sociedade, ativando um processo de transformação identitária ${ }^{14}$.

130 texto de Arroyo, além de ser utilizado como material de análise da literatura produzida sobre o tema da relação entre sindicalismo e identidade docente, pode e deve ser utilizado como fonte histórica para a análise do período, pois foi produzido no momento em que os acontecimentos analisados pelo objeto de pesquisa proposto estavam ocorrendo.

$14 \mathrm{Em}$ entrevista concedida à uma publicação em comemoração aos 25 anos do Sind-UTE, Arroyo ao rememorar seu texto escrito em 1980 considera que, em suas palavras, "o que coloquei nesse texto naquela ocasião, no meu entender, se confirmou. Essa identidade dos trabalhadores, que se revelou a partir da criação do Sindicato, não só levou à consciência da categoria, como teve repercussões importantíssimas na educação brasileira". ARROYO, Miguel. Profissionais da educação: trabalhadores(as) que lutam pelos seus direitos e por uma nova identidade. Entrevista concedida à Publicação especial comemorativa dos 25 anos do Sind-UTE. Belo Horizonte, dez.2004. p.26-28.
Esse processo de identificação dos docentes com os demais trabalhadores, como apontado por Arroyo (1980), pressupõe uma perspectiva intencional-reflexiva dos atores envolvidos nesse processo, pela qual teriam a "faculdade de causar permanência ou mudança na vida social através da ação" (DOMINGUES, 2004, p. 12). Para Arroyo (1980) a emergência de um novo contexto social pressupõe a existência de um sujeito com interesses uniformes e responsável pela direção das mudanças sociais. A nova identidade substituiria a anterior como decorrência da direção unívoca da transformação social. Essa proposição de Arroyo (1980) nos leva a questionar, como propõe Domingues (2004), os "níveis de centramento das subjetividades coletivas ${ }^{15 ",}$ pois, como nos afirma esse autor,

A noção de uma subjetividade centrada - bem definida e delimitada, com uma identidade clara, dirigida por centros decisórios bem estabelecidos - não pode mais ser tomada como evidente. (...) Conflitos, fontes múltiplas de dispersão, conhecimento limitado das condições da ação e das intenções de outros agentes, são variáveis que contribuem para aumentar ou reduzir os níveis de centramento e intencionalidade do sistema (DOMINGUES, 2004, p. 30).16

Desse ponto de vista, a identificação dos docentes como "trabalhadores em educação",

15 Para Domingues (2004), a subjetividade coletiva "não deve ser pensada como uma duplicação, no plano coletivo, de atores individuais ou como a mera soma da ação de indivíduos"'(p.36). Ela não seria “uma ação pura e simplesmente, nem um padrão estrutural. Ela é uma propriedade específica dos sistemas sociais, que pode ser descrita em termos estruturais, ao mostrar pessoa ocupando um certo número de 'posições' neles, porém não podem ser teoricamente reduzidas a isso"' (p.56).

16 "O centramento das subjetividades depende do potencial intrínseco e específico de cada sistema social. Para explicar os níveis de centramento, Domingues (2004) propõe uma fórmula, $\mathrm{NI}=\mathrm{NC}$ =MF (id, org), onde "ID (identidade) expressa a autopercepção e consciência, bem como a delimitação relativa dos sistemas sociais, ou seja, na medida em que eles são 'cientes' de si e demarcados em relação a outros sistemas sociais. ORG (organização) expressa a articulação dos sistemas sociais, que pode ser mais ou menos espontânea ou contar com centros decisórios de maior ou menor poder. Os NC (níveis de centramento) e NI (níveis de intencionalidade) variam de acordo com o que se passa com a identidade e a organização. (...) Quanto mais próximas da origem em sua variação independente uma da outra - a ID e a ORG, menores o NC e o NI; quanto maiores os valores da identidade e da organização, maiores os níveis de centramento e intencionalidade" (p. 31-32). 
em uma entidade homogênea, centrada, seria "insustentável", pois "esse centramento não é automático e necessário - ao contrário, é contingente, e sua realização é alcançada ou não de acordo com inúmeros fatores, a começar pelo sistema interativo em que aquelas coletividades se inserem" (DOMINGUES, 2004, p. 29).

A defesa de um processo no qual os docentes se identificariam com os demais trabalhadores, projetada por Arroyo (1980), nos leva a questionar, também, se estaríamos, neste período, diante do que Dubar (2005, p. 140-141) chama de "conflitos estruturantes da identidade", entre uma identidade herdada e uma identidade visada. Na perspectiva de Arroyo (1980), as identidades docentes herdadas já não responderiam às necessidades impostas pelas transformações pelas quais passava a sociedade naquele momento. As escolas e os docentes (seus trabalhadores) deveriam se sintonizar com essas transformações, com as lutas mais amplas, principalmente com as lutas pela democratização do acesso à escola. A "identidade visada" estaria em sintonia com as mudanças que viriam no sentido de transformar a função social da escola, de uma escola burguesa para uma escola que atenda aos interesses dos trabalhadores.

O artigo de Arroyo (1980) explicita no Brasil a associação entre lutas políticas/movimentos sociais/sindicais e a (re)construção de identidades sociais/profissionais nos sistemas públicos de educação básica do país. Implícita à análise desse autor está uma concepção ao mesmo tempo dicotômica e uniforme acerca da identidade social/profissional. Ondelutas sindicais e/ou movimentos sociais forjam identidades homogêneas a determinados grupos sociais e as contrapõem às representações forjadas anteriormente por grupos sociais hegemônicos [para o autor classes sociais] ${ }^{17}$.

Essa perspectiva inaugurada pelo texto de Arroyo (1980) inspirou estudos variados sobre a

170 discurso político e social do período alimenta práticas as mais diversas de oposição à ditadura militar existente no país. Nesse sentido, no período era frequente a construção de dicotomias a partir dos que defendiam a ditadura e aqueles que estavam contra. Eles e nós no período de luta pela redemocratização do país expressa um discurso que alimentava práticas de luta. construção das identidades docentes associadas às formas de organização e lutas sociais, ora enfatizando a organização sindical docente em si como fonte de formação de uma identidade social e profissional (Sader, 1998; Passos, 2005; Bulhões e Abreu, 1992; Gadotti, 1996; Biavatti, 2004; Loyo, 2001, Tiramonti, 2001), ora buscando associar a organização sindical docente com uma formação identitária ligada à ideia de "trabalhadores em educação" (Vianna, 2001; Arroyo, 2001; Furtado, 1996; Baldino e Afonso, 2002; Vicentini e Lugli, 2009; Ferreira, 2006, 2007), ou ainda questionando se de fato essa construção discursiva formulada por entidades sindicais docentes, que posiciona os/as professores/as como "trabalhadores em educação", tem sua correspondência na realidade (Costa, 1995; Oliveira, 2006; Souza, 1997).

A obra de Furtado (1996) traz alguns elementos que contribuem para a compreensão de um período que teria implicações significativas para a (re)formulação das identidades docentes. O autor, a partir da análise do processo de criação de uma das entidades representativas dos/as professores/as em Minas Gerais, a União dos Trabalhadores do Ensino - UTE-MG ${ }^{18}$ - no contexto do movimento grevista dos docentes em 1979, discute a maneira como é construída uma determinada identidade docente, a partir da construção de uma identidade do próprio movimento organizativo dos docentes.

Para Furtado (1996), a construção identitária dos docentes se daria mediante a fusão de três elementos: no primeiro nível estaria o sentimento de pertencimento a uma coletividade que "foi forjandose no próprio processo de construção da luta dos trabalhadores em educação, do que deriva inclusive o próprio conceito de 'trabalhadores em educação'” (FURTADO, 1996, p. 13.); o segundo nível referese às representações que se faz dos governos, figuradas como "inimigos"; no terceiro nível estaria a busca por "aliados" no seio do movimento de outras categorias profissionais (FURTADO, 1996).

Pode-se considerar que a configuração estabelecida por Furtado (1996), se referencia nas

18 Para uma história detalhada do surgimento da UTE - União dos Trabalhadores do Ensino - ver Furtado (1996), especialmente o capítulo 2, p.39-70. 
análises acerca dos imaginários sociais elaborada por Baczko (1984), que ao tratar das representações que determinada coletividade estabelece para si marcando uma distribuição de papéis e posições sociais, impondo certas crenças em comum considera que ao designar sua identidade coletiva, essas coletividades delimitam seu território e suas fronteiras, definem suas relações com os outros, formam as imagens dos amigos e dos inimigos, dos rivais e dos aliados, conservam e modelam as lembranças do passado, bem como projetam para o futuro suas crenças e esperanças (BACZKO, 1984, p. 32). Entretanto, resta ainda a indagação sobre o topos silenciado neste jogo relacional de representações. Ao designar identidades coletivas que, de acordo com Baczko (1984), demarcam fronteiras, definem-se relações, mas também se estabelece aqueles que na perspectiva foucaultiana são interditados, onde as relações identitárias demarcam um desconhecimento.

A identidade docente, no singular, para Furtado (1996) e também para Arroyo (1980), seria, portanto, um processo que se estruturaria a partir da práxis, da constituição de uma identidade forjada nas lutas e embates da categoria, uma identidade relacionada à ação, o próprio fazer forjando uma identidade, mas também sendo por ela constituído. Essa definição apresentada pelo autor é tributária do conceito de "experiência" de Marx, apropriado por E.P. Thompson, para o qual esta (a experiência) seria derivada do processo histórico vivenciado pelos atores sociais. Furtado (1996) aponta para o fato de que a identidade dos docentes pode ser entendida como "produto de uma dada configuração histórica que the confere uma identidade e uma dimensão cultural própria" (p. 129).

Arroyo (1980) e Furtado (1996), ao analisar a constituição de uma identidade docente acabam, porém, por considerá-la como uma tendência irreversível, não comportando uma esfera de tensão entre os sistemas estruturantes de identidades e processos de socialização, como destaca Dubar (2005), ou ainda, não evidenciando as contratendências existentes neste processo de reelaboração identitária, como proposto por Sarmento (2000). Nesse ponto reafirmamos que identidades profissionais são múltiplas, pois elas seriam fruto da articulação contínua de histórias pessoais com trajetórias sociais e culturais, não podendo por isso ser reduzida unicamente a um pertencimento de classe, ou a uma comunidade, ou mesmo à questões de gênero, etnia ou geração. Nesse sentido, a identidade profissional não é algo dado, estabelecido a priori, mas é parte de um processo contínuo de (re)elaboração, constituindo-se progressivamente a partir de processos específicos de socialização.

Ferreira (2006, 2007), em estudos realizados sobre a relação entre identidade, profissionalismo e sindicalismo docentes, aponta o seguinte questionamento: "que identidade está em cena quando os docentes se reúnem em organizações feitas à imagem dos trabalhadores manuais?" (FERREIRA, 2007, p. 380). Questiona ainda: por que não se agregam em associações profissionais, como existe em relação às profissões liberais? ${ }^{19}$ Para responder a essas questões, a autora investigou os motivos da sindicalização docente, que para ela seriam fruto não somente de uma escolha dentre várias, mas o resultado de mudanças no papel e valorização dos/as professores/as no sistema educacional, portanto relacionada a transformações identitárias sofridas pelos docentes.

Ferreira (2006) considera que a opção pela sindicalização, pela busca de uma determinada identidade de classe se apresenta como uma das imagens identitárias atuais, mas não seria a única, nem totalmente clara, pois muitos/as dos/as professores/as não se identificariam com a categoria "trabalhador". Para a autora, a sindicalização seria um indicador de uma das identidades da categoria. "A imagem 'proletária' é uma das existentes que convive com o desejo de profissionalização, isto é, essas identidades não necessariamente são excludentes" (FERREIRA, 2006, p. 231).

19 Há basicamente dois tipos de associações no âmbito profissional: as associações profissionais, que têm como característica o pertencimento obrigatório para o exercício da atividade, mesmo quando esses profissionais são contratados pelo mercado e não trabalham por conta própria. Como exemplo dessa situação podemos citar os advogados (exigência de registro na Ordem dos Advogados do Brasil - OAB). Outra forma de associação profissional seriam os sindicatos, que são de pertencimento opcional, que funcionam como elemento de pressão contra os empregadores. Em relação ao ensino público, o Estado assume a função de empregado (FERREIRA, 2007). 
Para Ferreira (2006), a relação estabelecida entre os/as professores/as e os seus sindicatos seria de naturezapragmática, naqual os docentes buscariam fazer frente aos processos de proletarização, em uma tentativa de resistir às perdas sofridas, através da sindicalização. De acordo com a autora, as razões que levam os docentes a se sindicalizarem não ocorrem necessariamente pela identificação com a categoria "trabalhadores em educação", mas por motivos de ordem instrumental, para obter vantagens individuais mais imediatas. Esse pragmatismo destacado por Ferreira (2006) difere da perspectiva desenvolvida por Arroyo (1980) que vê a identificação dos docentes com os demais trabalhadores como fruto de uma tomada de consciência de sua condição de classe.

O objetivo de Ferreira (2006) é, portanto, compreender as razões da sindicalização dos docentes, para tanto se utiliza da análise da constituição ou da formação de uma identidade determinada, não se prendendo à gênese e aos embates quando da constituição dessas identidades. A autora considera que a identificação com o termo "trabalhadores em educação" seria de caráter pragmático (Ferreira, 2006, p. 232). Essa consideração implica afirmar que o "núcleo central", nas palavras de Cattonar (2001), não seria afetado por essa identificação. Mesmo que a autora considere as contradições presentes nas formulações identitárias dos docentes, evidenciando tensões nos sistemas estruturantes de identidade - profissional ou proletário? - a autora acaba por reforçar a ideia de uma cultura profissional, que determina a identidade, mais estável. Essa postura acaba por reduzir as identidadesdocentesaquestõesligadasaocontexto de exercício da profissão, não comportando outras dimensões constitutivas dessa identidade, como seu aspecto relacional, especialmente como são estabelecidas as identidades para o outro (Dubar, 2005) ou ainda como as identidades docentes estariam relacionadas aos complexos processos de socialização nos quais os docentes estariam envolvidos, e se nesses processos diversas dimensões identitárias estariam presentes.

Em uma perspectiva que questiona se de fato a construção discursiva formulada por entidades sindicais docentes, que posiciona os/as professores/as como "trabalhadores em educação", tem sua correspondência na realidade, Oliveira (2006) aponta que depois de trinta anos passados das primeiras formulações acerca da construção de uma identidade, "os sindicatos não tiveram êxito em forjar a identidade de trabalhadores em educação, perseguida nas lutas sindicais classistas dos tempos de ditadura. É nítida a separação entre professores e funcionários dentro das escolas" (OLIVEIRA, 2006, p. 217). Haveria, na realidade, uma "identidade cindida ou jamais constituída" ( $p$. 218). A autora questiona em relação à identidade docente se de fato o conjunto de trabalhadores da escola se identificou em algum momento como "trabalhadores em educação". Questiona, ainda "em que medida essa identidade não foi uma criação artificial das lideranças políticas que tentaram transpor para dentro da escola valores de solidariedade e igualdade que jamais encontraram correspondência na prática desses trabalhadores" (OLIVEIRA, 2006, p. 220).

Essas afirmações e indagações reforçam a necessidade de se investigar o momento de emergência, nas lutas promovidas pelos docentes, do termo "trabalhadores em educação", pois as tensões, conflitos e contradições em torno dessa nomenclatura permanecem latentes até os dias de hoje, colocando em xeque a própria organização sindical dos docentes. No entanto, caberia confrontar tais indagações propostas por Oliveira (2006) com as proposições apresentadas por Dubar (2005), no sentido de se incorporar à análise o aspecto relacional da construção de identidades, especialmente a transação objetiva entre a identidade atribuída e a identidade assumida, pois "é na maneira como eles [os indivíduos] utilizam, pervertem, aceitam ou recusam as categorias oficiais que devem ser lidos os processos de identificação futura que implicam rearranjos permanentes tanto das crises quanto das categoriasidentitárias"(DUBAR, 2005, p. 145-146). Nesse sentido, mesmo diante da artificialidade do termo "trabalhadores em educação", como afirma Oliveira (2006), a atribuição do termo ao conjunto dos/as professores/as por uma de suas entidades representativas implicaria em um fator constituinte da construção de identidades docentes, mesmo que seja para contestá-lo. 
Poderíamos, também, confrontar a análise proposta por Oliveira (2006) quanto à identificação dos docentes com o termo "trabalhadores em educação" com a perspectiva apresentada por Domingues (2009), quando trata das chamadas "abstrações reais", relacionadas aos processos de "desencaixe ${ }^{20 "}$ que se desenvolvem com a modernidade. Utilizando as categorias analíticas apresentadas por Domingues (2009), podemos consideraraidentificaçãocomotermo "trabalhadores em educação" como uma "abstração real", pois "para ser funcional esse tipo de identidade deve ser abstrato, porém também real" (DOMINGUES, 2009, p. 39), ainda de acordo com esse autor essas "abstrações" não deixam de ser reais, "posto que presidem a tecitura da consciência dos sujeitos e organizam as instituições sociais" (DOMINGUES, 2000, P. 50). Podemos dizer que diante do contexto de luta contra a ditadura militar, de degradação das condições de trabalho e salariais dos docentes, a identificação com os demais trabalhadores tinha um substrato real, porém marcada por uma "utopia homogeneizante" que geralmente "demonstra uma aguda tendência a rejeitar as particularidades" (DOMINGUES, 2009, p. 39).

\section{Considerações finais}

A partir da literatura analisada buscou-se traçar um referencial teórico que permitisse compreender a complexidade dos processos de construção identitária dos docentes, bem como do próprio termo "identidade". Buscaram-se nos/as autores/ as analisados/as elementos que pudessem ser cotejados com o pressuposto apresentado de que há uma tensão permanente que perpassa as formulações identitárias dos docentes, tensão evidenciada na relação destacada por Dubar (2005) entre os aspectos relacionais e biográficos - na constituição das identidades para o outro e das identidades para si - e entre as identidades herdadas e as identidades visadas. A construção

20 Domingues (2004), em teorização inspirada nos trabalhos de Marx, Simmel, Giddens e, em parte, de Parsons, considera que a modernidade se desenvolve através de "desencaixes", que são processos que "arrancam as pessoas de contextos tradicionais, rompendo relações de subordinação pessoal e destruindo identidades estáveis, ou, em princípio, dadas como tais" (p. 87). de identidades docentes, então, passa a ser vista como um processo dinâmico, que pode conhecer fases de rupturas, de continuidades ou de reelaborações, que comporta múltiplas dimensões, seja relacionado aos contextos sócio-históricos, seja relacionado às múltiplas experiências relacionais individuais e coletivas pela quais passam os docentes, tanto no exercício profissional quanto no que diz respeito aos seus pertencimentos sociais.

Pode-se perceber nas obras analisadas duas vertentes básicas de compreensão do processo de construção das identidades docentes. Uma vertente que privilegia a construção das identidades a partir dos processos de socialização, aqui exemplificada nas obras de Dubar (2005) e Cattonar (2001), e outra que considera a construção identitária a partir das lutas sociais e embates da categoria, como fazem Arroyo (1980) e Furtado (1996).

Em relação à primeira vertente, há uma dicotomia acentuada nas formas em que se estabelecem as relações entre os docentes e os "outros". Esta dicotomia se apresenta nas formulações de Cattonar (2001) em relação ao que a autora chama de "cultura profissional partilhada", evidenciando "normas-regras-valores" próprios aos docentes, portanto se diferenciando dos "outros". Fica evidente, ainda, nas proposições de Dubar (2005), quando este autor afirma que as estratégias identitárias consistem em reduzir a distância entre as "identidades para si" e as "identidades para o outro" (Dubar, 2005, p. 140) e que essa "negociação identitária" "implica fazer da qualidade das relações com o outro um critério e um elemento importante da dinâmica das identidades" (p. 140). Percebe-se, portanto, a centralidade dos processos relacionais, a demarcação de fronteiras em relação ao outro para o estabelecimento das identidades docentes.

No entanto esses autores demonstram a complexidadedasformas deconstruçãoidentitárias, evidenciando que não se trata de processos lineares com resultados pré-estabelecidos. Seja um "núcleo central" de uma identidade profissional, sejam tentativas de aproximação de identidades para si e para o outro, sejam tensões entre processos estruturantes, a resultante não está dada previamente e nem é uniforme. 
A segunda vertente, ao considerar que a construção identitária se efetiva a partir das lutas sociais e embates da categoria, estabelece um padrão diferenciado na forma de se compreender a relação dos docentes com o "outro". Nessa proposiçãonãoseprocuraestabelecerdemarcações nítidas, ao contrário, o que se evidencia são os pontos em comum, os aspectos que destacam uma associação de propósitos com o "outro", no caso, todos os trabalhadores assalariados. Aqui, o que se percebe é a centralidade da ação reivindicatória nas lutas macrossociais como elemento estruturante das identidades docentes.

No entanto, essa segunda vertente de análise, participa de uma apreensão dicotômica das imagens "trabalhador" versus sacerdócio, missão, desconsiderando as demais formulações identitárias que transitam no espaço discursivo das entidades docentes e percebendo tais formulações identitárias de forma pouco dinâmica. Nessas correntes analíticas determina-se um grau de eficiência coercitiva bastante acentuado em relação aos sistemas sociais, no caso, as associações e sindicatos docentes, o que Domingues (2004, p. 51), vai denominar de "causalidade condicionante", na qual os atores individuais seriam condicionados por esses sistemas sociais. Seria como se as entidades docentes tivessem a capacidade de determinar e impor certas formulações identitárias que seriam incorporadas pelos atores individuais.

Esse processo de identificação dos docentes com os demais trabalhadores assalariados, reelaborando uma identidade ligada à imagem do "trabalhador do ensino" pode ser considerada, na perspectiva apresentada por Domingues (2000), como uma das formas mais particularizadas nas quais se apresenta os novos "reencaixes" da modernidade, ou novas identidades individuais e coletivas, que seria a pertença à classe operária, como é o caso da construção discursiva formatada pela UTE-MG. Mas, como destaca ainda Domingues (2000, p. 51), esses novos processos de "reencaixe" se vêem permanentemente em destroços, forçando as instituições sociais, como é o caso dos sindicatos e associações de docentes, a buscarem modificações constantes que possam dar o mínimo de segurança e de reconhecimento identitário a seus membros.
Mas de onde adviria esse "mínimo de segurança", o que permitiria, por exemplo, que uma entidade como a UTE-MG conseguisse, ao menos discursivamente, (re)elaborar uma identidade relacionada à imagem do "trabalhador do ensino"?

Para responder a essa questão podemos nos apropriar da noção de "subjetividades coletivas", desenvolvida por Domingues (2004). Para esse autor os sistemas sociais, dentre eles as associações e sindicatos, podem ser compreendidos a partir dessa noção, que para melhor compreensão devem ser considerados os seguintes pressupostos: primeiro, são detentoras de uma "causalidade coletiva", que se estabeleceria a partir dos sistemas de interação constituintes das relações sociais; segundo, deve-se considerar o descentramento do sujeito, destacando-se seu caráter essencialmente relacional; terceiro, deve-se considerar, também o centramento contingente de cada sistema social, que não seria algo automático. A partir desses pressupostos, Domingues (2004, p. 30) conclui que uma subjetividade coletiva centrada não seria algo evidente e que, portanto devem-se analisar os níveis de centramento e causalidade dessas subjetividades. Esses níveis de centramento dependeriam de duas variáveis, a identidade e a organização desses sistemas sociais. A primeira expressaria a "autopercepção e consciência, bem como a delimitação relativa dos sistemas sociais, ou seja, na medida em que eles são 'cientes' de si e demarcados em relação a outros sistemas" (DOMINGUES, 2004, p. 31); já a organização seria a própria articulação dos sistemas sociais. A partir dessas duas variáveis, poderia, segundo o autor, se definir o nível de centramento das subjetividades coletivas, pois quanto maior a "autopercepção e consciência" e os níveis de organização, maior os níveis de centramento e intencionalidade de um sistema social (Domingues, 2004, p. 25-32).

A partir dessas formulações, Domingues (2004, p. 32-33) vai estabelecer uma tipologia, de caráter prático e aproximativo - como toda tipologia - para classificar os sistemas sociais de acordo com seus níveis de centramento. A partir dessa classificação poderíamos considerar que a UTE-MG, por exemplo, se enquadraria no tipo "categoria", como um subgrupo, que segundo esse autor pode atingir razoável nível 
de centramento, pois poderia alcançar grande identidade ("autopercepção e autoconsciência de si"), mas, contudo, a heterogeneidade que caracteriza esses tipos de grupo tende a diminuir seu nível de centramento. Portanto, essa entidade teria sim um nível de centramento capaz de elaborar uma determinada forma identitária, construindo aquele "mínimo de segurança" em relação a um reconhecimento identitário.

Com essa aproximação das formulações de Domingues (2004) queremos afirmar que a identidade de "trabalhador do ensino", ou outras formulações relacionadas às identidades profissionais docentes, apesar de uma determinada "intencionalidade coletiva" projetada pelas "subjetividades coletivas", no caso em questão por suas entidades representativas, são sempre variáveis e contingentes, marcadas por conflitos, tensões, rupturas, permanências.

Acompanhando Martuccelli (2002), podemos afirmar que "a identidade é hoje uma relação e jamais uma substância, mas uma relação que deseja se mostrar como uma substância" ( $p$. 426. Tradução nossa). Reafirmamos, dessa forma, o caráter transitório e fundamentalmente relacional das constituições identitárias, ligadas a contextos históricos específicos, mas também seu caráter afirmativo, sua busca constante por coerência e estabilidade, que dê a sensação aos indivíduos de se reconhecerem como parte de uma coletividade, fios tecendo as complexas tramas das relações sociais.

\section{Referências Bibliográficas}

ARCHER, Louise. The new neoliberal subjects? Young/er academics constructions of Professional identity. Journal of Education Policy. Vol.23, n.3, may, 2008, p. 265-285.

ARROYO, M. Ofício de mestre; imagens e auto-imagens. 3. ed. Petrópolis: Vozes, 2001.

ARROYO, Miguel. Operários e educadores se identificam: que rumos tomará a educação brasileira? Educação e sociedade. São Paulo, v.2, n.5, jan.1980.

AVALOS, B. El nuevo profesionalismo: formación docente inicial y continua. In: FANFANI, Emílio Tenti (comp.). El ofício de docente: vocación, trabajo y profesión en el siglo XXI. Buenos Aires: Siglo XXI Editores, 2006.

BACZKO, Bronislaw. Les imaginaires sociaux: mémoires et espoirs collectifs. Paris: Payot, 1984.

BALDINO, J.M.; AFONSO, L.H.R. Formação de profissionais da educação: a intervenção dos sindicatos. In: BRZEZINSKI, Iria (org.). Profissão Professor: identidade e profissionalização docente. Brasília: Plano Editora, 2002. 196 p.

BAUMAN, Zygmunt. Identidade: entrevista a Benedetto Vecchi. Rio de Janeiro: Zahar, 2005.

BIAVATTI, Vânia Tanira. Sindicalismo e sindicatos docentes: modos de subjetivação docente. VIII Congresso Luso-afro-brasileiro de Ciências Sociais. Set.2004.

BULHÕES, M. da G.; ABREU, M. A luta dos professores gaúchos (1979/1991): 0 difícil aprendizado da democracia. Porto Alegre: L\&PM, 1992.

CATTONAR, Branka. Les identités professionnelles enseignantes. Ebauche d'um cadre d'analyse. Cahier de Recherche du GIRSEF, n.10, mar. 2001. < Disponível em: http://www.girsef.ucl.ac.be/cahiers.html >.

COSTA, Marisa C. Vorraber. Trabalho docente e profissionalismo. Porto Alegre: Sulina, 1995.

DOMINGUES, José Maurício. A América Latina e a modernidade contemporânea - uma interpretação sociológica. Belo Horizonte: Editora UFMG, 2009 .

DOMINGUES, José Maurííio. Ensaios de sociologia. Belo Horizonte: Editora UFMG, 2004.

DOMINGUES, José Maurício. Desencaixes, abstrações e identidades. In. AVRITZER, L.; DOMINGUES, J.M. Teoria social e modernidade no Brasil. Belo Horizonte: Editora UFMG, 2000, p. 38-60.

DUBAR, Claude. A socialização: construção das identidades sociais e profissionais. São Paulo: Martins Fontes, 2005.

ESTEVE, José M. Identidad y desafios de la condición docente. In. FANFANI, Emílio Tenti (comp.). El ofício de docente: vocación, trabajo y profesión en el siglo XXI. Buenos Aires: Siglo XXI Editores, 2006.

FERREIRA, Márcia Ondina Vieira. Notas sobre as relações entre identidade e sindicalismo docentes. Educação e Sociedade, vol.28 n.99. 
Campinas, p. 377-399 Mai./Ago. 2007.

FERREIRA, Márcia Ondina Vieira. Somos todos trabalhadores em educação? Identidades docentes desde a perspectiva de sindicalistas. Educação e Pesquisa. vol.32 n.2 São Paulo Maio/Agosto. 2006.

FURTADO, João P. Trabalhadores em Educação: experiência, imaginário e memória sindical nos anos 80 e 90. Ouro Preto: Ed. UFOP, 1996.

GADOTTI, M. Estado e sindicalismo docente: 20 anos de conflitos. Revista ADUSP, São Paulo, p. 14-20, dez. 1996.

HALL, Stuart. A identidade cultural na pós-modernidade. Rio de Janeiro: DP\&A, 2006.102 p.

LOYO, Aurora. Los sindicatos docentes en América Latina. Entre la lógica laboral y la lógica profesional. Revista Iberoamericana de Educación. Madri, n.25, jan./abr. 2001, p. 65-81.

MARTUCCELLI, Danilo. Grammaires de l'individu. Paris: Gallimard, 2002.

OLIVEIRA, Dalila Andrade. Regulação educativa na América Latina: repercussões sobre a identidade dos trabalhadores docentes. Educação em Revista-Revista do Programa de Pós-Graduação em Educação da FAE/UFMG, Belo Horizonte, n.44, p. 209-227, dez. 2006.

PASSOS, Mauro. Historiando embates e conquistas da profissão docente em Minas Gerais (1977-2004). In: PEIXOTO, Ana Maria Casasanta; PASSOS, Mauro (orgs.). A escola e seus atores: educação e profissão docente. Belo Horizonte: Autêntica, 2005. p. 29-52.

RODRIGUES, Maria de Lurdes. Sociologia das profissões. 2. ${ }^{\mathrm{a}}$ ed. Oeiras, Portugal: Celta, 2002.

SADER, Éder. Quando novos personagens entraram em cena: experiências e lutas dos trabalhadores da Grande São Paulo - 19701980. Rio de Janeiro: Paz e Terra, 1986.

SARMENTO, Manuel Jacinto. Lógicas de acção nas escolas. Lisboa, Instituto de Inovação Educacional, 2000.

SOUZA, A. N. de. Movimento sindical docente: a difícil trajetória. In: LEITE, M. de P. (Org.). O trabalho em movimento: reestruturação produtiva e sindicatos no Brasil. Campinas: Papirus, 1997. p. 113-174.

TIRAMONTI, G. Sindicalismo docente y reforma educativa en la América Latina de los '90. In: TIRAMONTI, G.; FILMUS, D. (Coord.). Sindicalismo docente \& reforma en América Latina. Buenos Aires: FLACSO/Temas, 2001. p. 111-146.

VIANNA, Cláudia. A produção acadêmica sobrea organização docente: ação coletiva e relações de gênero. Educação e Sociedade. Campinas, v.22, n.77, p. 100-130, dez. 2001.

Recebido em maio de 2010

Recebido em agosto de 2010 